$16^{\text {th }}$ International Congress of Metrology, 14002 (2013)

DOI: $10.1051 /$ metrology/201314002

(C) Owned by the authors, published by EDP Sciences, 2013

\title{
Objectifying user attention caused by visually perceived product components
}

\author{
Markus Köhler ${ }^{1, a}$, Björn Falk ${ }^{1}$, Robert Schmitt ${ }^{1}$ \\ ${ }^{1}$ Chair for Metrology and Quality Management, RWTH Aachen University, Steinbachstr. 19, 52074 Aachen, \\ Germany
}

\begin{abstract}
Customers base their emotional evaluation on perceived product components. Thus, for the success of a company it is important to measure customers' perception objectively and integrate this information into processes of user orientated product design. This paper presents findings of identifying relevant product components and linking them with semantic concepts using Eye-Tracking. To validate results, the comparison with self-reporting-methods identifies similarities and differences between explicit expressed and implicit recorded customer requirements. The validation of the presented approach was conducted within user studies analyzing products with different levels of complexity.
\end{abstract}

\begin{abstract}
Des clients fondent leur évaluation émotionnelle sur les attributs des produits qui sont d'après leur avis important. Pour cette raison c'est considérable pour le succès d'une entreprise de mesurer objectivement la perception des clients et d'utiliser ces informations pour le procès d'un design de produit qui est orienté au consommateur. Cette publication présente des résultats de recherche qui s'occupe avec l'identification des attributs importants des produits. Ces résultats sont combinés avec des concepts sémantiques par l'utilisation de «Eye tracking ». Pour la validation des résultats, la comparaison avec des méthodes qui s'exploitent soi-même a identifié des différences et convergences entre des exigences des clients qui sont explicitement articulées ou implicitement enregistrées. La validation de l'approche présentée a été accomplie par des études qui analysent des produits possédants des niveaux de complexités différentes.
\end{abstract}

\section{Introduction and motivation}

Perceived Quality is linked to emotions and emotions are affecting purchasing decision. The active design of Perceived Quality fosters the development of emotionally inspiring product characteristics. [1] Therefore, in order to ensure a high product quality perception companies have to integrate this awareness especially in early steps of product development and design. [2, 3] Measuring objectively customers' attention and emotions that are related to physiological signals is an entrepreneurial challenge in order to design a product that evokes a positive emotional response. Additionally, the human perception is highly complex consequently it cannot be measured deficiently only by customer surveys. Thus, especially for the active design of aesthetic product characteristics there is a need to combine visual product impressions analyzed by gaze tracking with different modalities for capturing and objectifying emotions. This paper presents an excerpt of approaches to survey and to objectify information about the customer's subjective product perception and attention systematically. [4]

\footnotetext{
${ }^{\mathrm{a}}$ Corresponding author: m.koehler@wzl.rwth-aachen.de
}

\section{Perceived quality and users' attention}

\subsection{Perceived Quality}

The active design of perceived product quality and the individual interpretation of the product realization is an important lever to differentiate from competitors. [5] The term Perceived Quality is defined as the cognitive and emotional comparison between product characteristics and customer requirements and needs. This comparison is based on conscious and unconscious perception and is related to the experiences and expectations of the specific target group (see Fig. 1 and [6]).

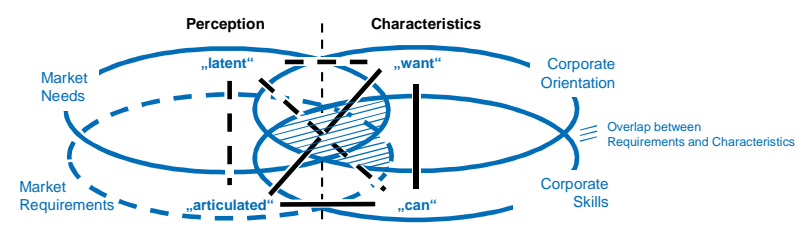

Figure 1. Understanding of Perceived Quality. (Based on [7]) 
Therefore, a structured approach to quality perception from the customers' perspective should be systematically applied to survey and to specify product attributes that are relevant to the perception and attention in order to objectify the customer's quality judgments. [5] About 80 per cent of all the information influencing people's decisions is gathered visually [8]. Thus, especially during early phases of product development process (PDP) the visual impression (e.g. by using Eye-Tracking) is often more decisive than other impressions (e.g. haptic, acoustic) to evoke emotions. [9] The developed approach focuses measuring objectively the visual aspects of the perception of products and quality attributes. [4]

\subsection{Measuring user attention via Eye-Tracking}

The direct observation is the oldest and simplest approach of registering the eye movement of an user. Although, movements of $1^{\circ}$ are detectable for the observer, those movements are not quantifiable and, subsequently, it is not comparable with modern Eye-Tracking systems. [10] Eye-Tracking is one of the most important techniques to evaluate the visual product impression and it is applied to deduce the attention provoked by perceived product components. Thereby, fixations, saccades and scan paths are important key figures to generate valuable input data for product development. Fixations are moments when the eyes rest in one position, taking in or encoding information, saccades are rapid eye movements between fixations and scan paths combine a sequence of saccadefixation-saccade. Other metrics as gaze (look), pupil changes and blink rates are also studied. $[11,12,13]$

\subsection{Established methods and concepts for objectifying Perceived Quality information}

Established concepts for objectifying Perceived Quality data and for integrating gathered information into emotional and affective engineering are: Quality Function Development (QFD), Conjoint Analysis, Means-EndAnalysis or Kansei Engineering. Basically, these concepts lack the ability of quantifying emotions by measuring physiological signals: E.g. Kansei Engineering only focuses the description of customers' impressions by semantic words and disregards unconscious impressions. $[14,4]$ To transfer user opinion into objective product characteristics, mainly, these methodologies rely on questionnaires. However, these methods depend on individual circumstances, expectations and requirements (articulated but very often subjective data, see Fig. 1). Furthermore, because of the complexity of products and slight differences users may have problems in deciding between product alternatives. Otherwise, users may modify their opinion if they do not want to express true feelings, since they feel inhibited or because of the unconscious influence by the experimenter $[15,16,4]$.

\section{Objectifying user attention}

This paper presents an excerpt of a methodology and selected results of a study trying to solve different entrepreneurial challenges. At the beginning of a PDP there is a need to align the target group's product understanding with the company's strategy. Furthermore, it is crucial to link this product understanding expressed in semantic concepts with perceived product components. The approach applied in this paper is using Eye-Tracking and is based on the fact that the gaze track is affected by current thoughts. (see Fig. 2 and [17])

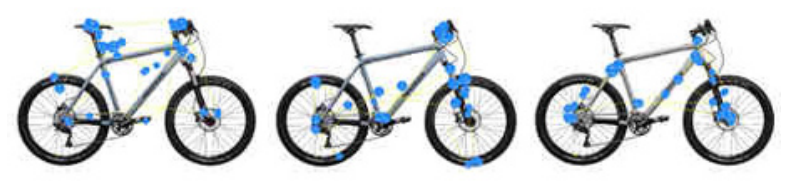

Figure 2. Individual gaze tracks influenced by semantic concepts (left: premium, middle: sportive, right: reliable)

\subsection{Research questions and general methodology}

The following research questions are of importance for entrepreneurial aspects: How can the customer's and company's product understandings be aligned in general? Can Eye-Tracking be applied to detect relevant product components? Do product strategies have any influence on the attention of the most important product components?

Embedded in an holistic methodology [4, 1] the following methods and steps are applied to answer the aforementioned research questions:
systematic collection and reduction of product strategies
applying semantic concepts to differentiate between design alternatives on several levels of product structure
gathering the conscious product evaluation and decisions between design alternatives via applying questionnaires
- identification of the most relevant components of a special product design regarding the user attention applying Eye-Tracking to investigate the user attention related to the aforementioned methods

\subsection{Experimental design and analysis procedure}

In several user studies during the research project CONEMO the presented methodology was applied and investigated. [4, 1] In this paper results are presented considering a case study on different design alternatives of mountain bikes. The study was based on the question how product designers should evaluate and decide between different design components. The base version of a mountain bike was varied in two design factors: the fork and the color of the frame, all other components remained. Each factor has two levels. (see Tab. 1) The modified fork was also more expensive than the one that the base mountain bike was equipped with.

Table 1: Different alternatives analyzed in the study

\begin{tabular}{cccc}
\hline \multicolumn{2}{c}{ color of frame } & \multicolumn{2}{c}{ fork } \\
\hline grey & blue & base & modified
\end{tabular}




\subsubsection{Collection and reduction of semantic words}

Several methods such as interviews with experts, internet research and focus group workshops were applied in order to generate an overview of semantic concepts. In the approach, semantic concepts are words representing the emotional description of the studied mountain bikes.

Afterwards, the company's point of view, as a bike specialized community, was aligned in order to systematically reduce the words. A company oriented questionnaire with 22 employees lead to the following and most important semantic words: sportive, premium and reliable. A Kano-study emphasized the importance of these semantic words by characterizing sportive and reliable as must-be requirements and premium as a onedimensional feature (see Fig. 3). [18]

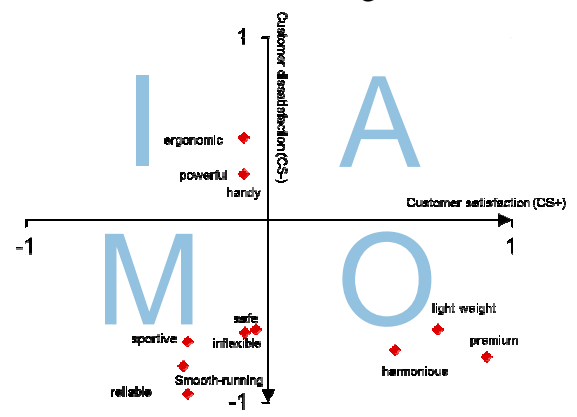

Figure 3. Classification with Kano model.

In addition, the significance of reliable and premium with regard to their characterization could be shown by Fong's statistical significance test (see Tab. 2) [19].

Table 2. Most important semantic words characterization

\begin{tabular}{ccc}
\hline Concept & CS $^{+}$ & CS $^{-}$ \\
\hline sportive &,- 33 &,- 65 \\
premium &, 90 &,- 75 \\
reliable &,- 33 &,- 95
\end{tabular}

\subsubsection{Definition of areas of interests}

For reasons of study design and to reduce systematic influences on the results of Eye-Tracking, the products were presented in the same manner (e.g. same angle, same size, same background). One result of preliminary studies was that the duration that each picture should be presented depends on product type and the complexity of the product structure. It was shown that pictures such as bikes should be presented between 10 and $15 \mathrm{sec}$. That way, the attention and the emotional response of the user can be recorded. [4]

By using system analysis and the structured approach towards quality perception, the bikes were clustered into five areas of interest representing visual clusters of perception [7]: saddle, handlebar, frame, wheels and fork. As shown in former studies, the amount of perception clusters also depends on the complexity of the product (e.g. for a car exterior about 20 areas of interests could be defined [4]).

\subsubsection{Study design and measurement equipment}

After the determination of semantic words and perception clusters, the Eye-Tracking schedule was organized. At the beginning (phase 1) a picture of each design alternative was presented to measure reference values. In phase 2 of the study, each bike was presented in relation to each semantic word in order to point out the influences of semantic concepts on the attention and the most relevant components. At the end, pairwise comparisons of all designs and an entire comparison were conducted. All in all, the schedule had a length of 7.5 minutes.

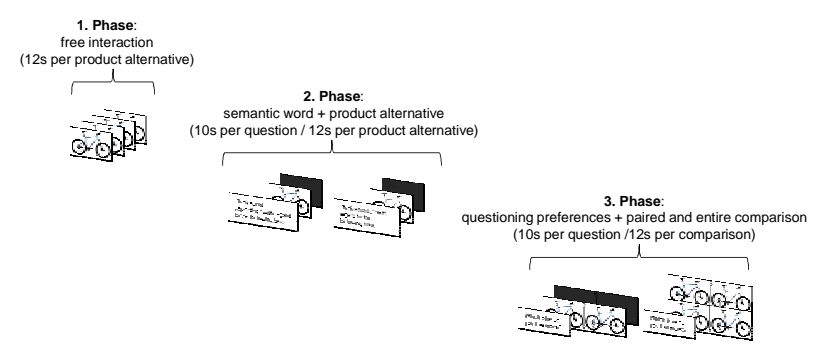

Figure 4. Phases of the Eye-Tracking study schedule.

A video-based combined pupil/corneal reflection EyeTracker, a so called remote Eye-Tracker, was used in order to measure the customers' eye movements such as fixations, saccades and scan paths. The system consists of two infrared light sources, two video cameras and a twodimensional screen. Remote Eye-Tracking systems are characterized as non-contact measurement systems, because there are no mechanical components as cables or chin rests and consequently no contact between participant and measuring system. Thereby, an infrared light is reflected from the eye and captured by a video camera to analyze eye movements from changes in reflections, which are send out by the center of pupil. A pupil/corneal Eye-Tracker has some essential advantages with regard to head movements. Movements of several centimeters have no influence on the results. Moreover, the system is able to reconstruct the gaze vectors if the participant moves the head out of the recorded area or blinks without any negative effects. In addition, beside the low influence on the user the used system can be characterized by a short calibration time. [20, p. 18]

For reason of contrasting results of explicit and implicit user opinion, the Eye-Tracking was combined with an ordinary questionnaire conducted with tablets. It consists of questions about relevant design components and preferences between the identical four design alternatives. Furthermore two of the four bikes were placed in a store to realize a physical comparison.
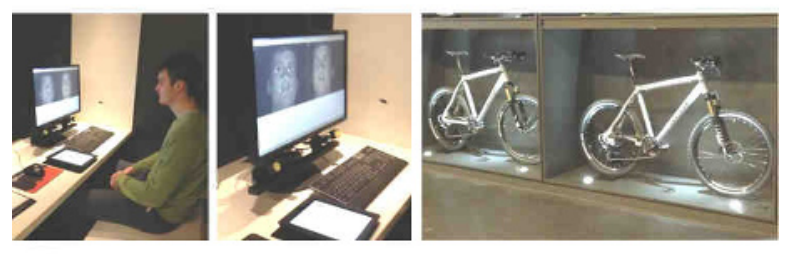

Figure 5. Study consisting of Eye-Tracking study, tabletbased questionnaire and interaction within bike store. 
The Eye-Tracking study, the questionnaire and the evaluation within the bike store built up an holistic study design simulating different steps of PDP (see Fig. 5).

To reach customers of the target group, the study was conducted at a bike store. Customers were asked to participate in a study about mountain bikes. The participants $(n=11,18$ to 45 years, mean $=26.36)$ were all well-informed about brands and technical details. On a 7-point-scale (1: very low; 7: very high) the users were asked about their fascination for bikes in general $($ mean $=$ 5.73 and $s d=1.35$ ) and specially for mountain bikes ( mean $=5.36$ and $s d=2.2$ ). Mainly, the users base their purchase decision on the appearance in the store (10) or recommendations (7) or even on pictures from the internet (5) or catalogues (2). Especially the last two options are reasons to implement a screen-based EyeTracking system in order to objectify user's opinion.

First, the users were instructed and seated about $60 \mathrm{~cm}$ in front of the screen. Secondly, the Eye-Tracking system was calibrated (accuracy: left eye: mean deviation $=1^{\circ}$, $\mathrm{sd}=0.29^{\circ}$; right eye: mean deviation $=0.9^{\circ}, \mathrm{sd}=0.25^{\circ}$ ). Afterwards the aforementioned study was conducted (see Fig. 4) and compared with results of the questionnaire.

\subsubsection{Statistical analysis}

To compare the effect of semantic concepts on the time ratios of relevant quality attributes a within subjects ANOVA was conducted. Furthermore, for the bike alternatives and for the significant effects post hoc pairwise comparisons (analysis of T-Paired-tests) were used to investigate which semantic word differs significantly (e.g. $\mathrm{p}<0.1$ ). Eventually, educated recommendations for product design were derived.

\subsection{Results}

\subsubsection{Identification of most relevant product components}

Following a pareto analysis it could be revealed that during the free examination of the products alternatives more than $80 \%$ of the whole mean time the users observed three of five product attributes: the frame, the wheels and the fork. (see Tab. 3). The most important attributes were also of similar importance in the design of the four mountain bike alternatives.

Table 3: Time ratios for the defined areas of interests

\begin{tabular}{ccc}
\hline Item & Mean & SD \\
\hline saddle &, 085 &, 0797 \\
handlebar &, 093 &, 0725 \\
frame &, 434 &, 1841 \\
wheels &, 195 &, 1093 \\
fork &, 170 &, 0940
\end{tabular}

\subsubsection{The effect of semantic concepts on user's attention}

To analyze the effect the subjects were shown a set of stimuli: the factor bike with four levels and the semantic concepts with four levels (free interaction, sportive, premium, reliable) as well. For each product attribute and for each of the five areas of interests (perception clusters) the time ratio was recorded. A repeated measures ANOVA was conducted to test the differences between means of fixation time ratios for significance. To have a first idea of the effect of semantic words the diagrams for the estimated marginal means for the time ratio of the selected product attributes (Fig. 6 and 7) were analyzed.

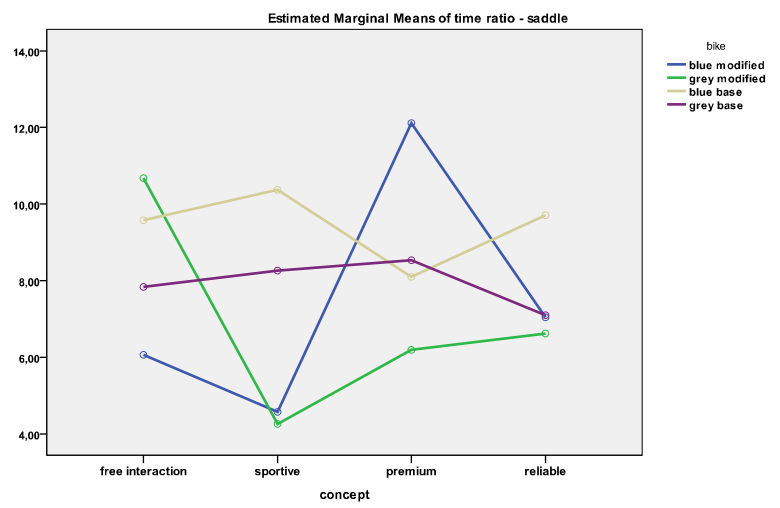

Figure 6. Means of time ratio for saddle.

For purposes of illustration two areas of interest are selected for analyzing results. On the one hand, it could be concluded that the saddle of the grey modified bike (green line in Fig. 6) was significantly more focused while thinking in a sportive concept in comparison to free interaction $(\mathrm{T}(9)=2.021 ; \mathrm{p}=.0740)$ and the blue modified bike (blue line) was significantly more focused while thinking of sportive than premium $(\mathrm{T}(9)=-2.131 ; \mathrm{p}$ $=.0619)$. This shows that semantic words can affect customers' emotion.

On the other hand, it could be revealed that the blue and grey modified bike (blue and green line in Fig. 7) were significantly more focused than the grey base bike (violet line in Fig. 7, $\mathrm{T}(8)=2.6804 ; \mathrm{p}=.0279$ and $\mathrm{T}(8)=$ 2.4044; $\mathrm{p}=.04288)$. That implies that the modified fork was assessed more sportive than the base fork what could be validated by the questionnaire.

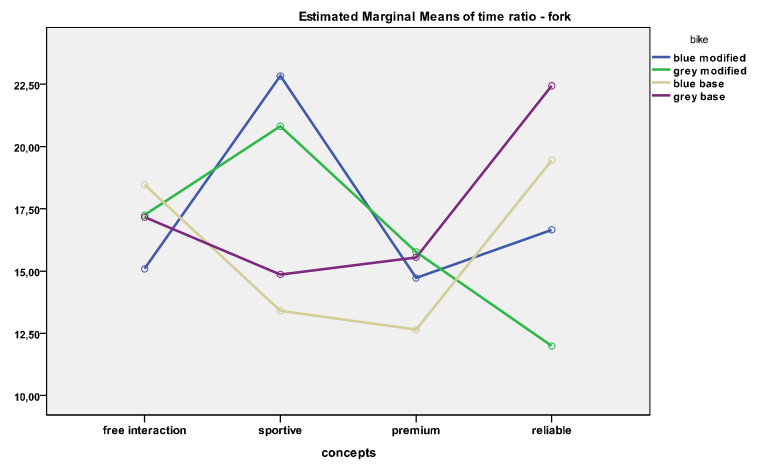

Figure 7. Means of time ratio for fork. 


\subsubsection{Identifying preferences}

As shown before, there could be a difference between explicit articulated and implicit recorded or even latent customer requirements. Therefore, the comparison between self-reporting techniques and Eye-Tracking results was conducted asking for the preference of the bike alternatives. The results of the pairwise comparisons of Eye-Tracking were analyzed by using a valuation method which consists of three numerals (2: significant difference concerning the fixations of a bike, 1: no significant difference and 0 : significant difference concerning the fixations against the bike) whereas the analysis of the pairwise comparison of the questionnaire only uses two numerals (1: higher preference and 0: lower preference).

The analysis of Eye-Tracking (see Tab. 4) revealed a higher preference of bikes with the modified fork, especially of the grey type. Furthermore, there were significant differences in relation to the two pairwise comparisons which compared the bikes which only differed with regard to the fork $(\mathrm{T}(10)=1.876 ; \mathrm{p}=$ .0467 ) for the modified blue one and $\mathrm{T}(10)=2.541 ; \mathrm{p}=$ .0158 for the modified grey one).

Table 4. Pairwise comparison - Eye-Tracking

\begin{tabular}{c|cccc|c}
\hline Bike & $\begin{array}{c}\text { blue } \\
\text { modi- } \\
\text { fied }\end{array}$ & $\begin{array}{c}\text { grey } \\
\text { modi- } \\
\text { fied }\end{array}$ & $\begin{array}{c}\text { blue } \\
\text { base }\end{array}$ & $\begin{array}{c}\text { grey } \\
\text { base }\end{array}$ & \\
\hline blue modified & $\mathrm{x}$ & 0 & 2 & 1 & 3 \\
grey modified & 2 & $\mathrm{x}$ & 1 & 2 & 5 \\
blue base & 0 & 1 & $\mathrm{x}$ & 1 & 2 \\
grey base & 1 & 0 & 1 & $\mathrm{x}$ & 2
\end{tabular}

The questionnaire validated the fact that the modified fork is preferable to the base fork by revealing similar results (see Tab. 5). Additionally, the questionnaire showed that the grey bike with modified fork was evaluated as most sportive. An entire comparison also revealed the preference of the modified fork (see Tab. 6).

Table 5. Pairwise comparison concerning preference Questionnaire

\begin{tabular}{c|cccc|c}
\hline Bike & $\begin{array}{c}\text { blue } \\
\text { modi- } \\
\text { fied }\end{array}$ & $\begin{array}{c}\text { grey } \\
\text { modi- } \\
\text { fied }\end{array}$ & $\begin{array}{c}\text { blue } \\
\text { base }\end{array}$ & $\begin{array}{c}\text { grey } \\
\text { base }\end{array}$ & \\
\hline blue modified & $\mathrm{x}$ & 3 & 6 & 6 & 15 \\
grey modified & 5 & $\mathrm{x}$ & 8 & 8 & 21 \\
blue base & 1 & 0 & $\mathrm{x}$ & 2 & 3 \\
grey base & 1 & 1 & 4 & $\mathrm{x}$ & 6
\end{tabular}

Table 6. Entire comparison - Eye-Tracking

\begin{tabular}{ccc}
\hline Bike & Mean & SD \\
\hline blue modified & .343 & .0583 \\
grey modified & .236 & .0678 \\
blue base & .160 & .0610 \\
grey base & .261 & .0723
\end{tabular}

\section{Conclusions and future directions}

The visual impression of products recorded and analyzed by the duration of fixation as well as the general visual comparison between product alternatives are valuable input data for the product development. In order to link the product strategy with product components, the paper presents results applying the fact that the gaze track is 
affected by current thoughts. Findings are presented and statistically analyzed, relating changes in user attention on perceived product components and on design alternatives with semantic concepts. The presented approach and the elaborated results of Eye-Tracking studies were compared and combined with ordinary questionnaires conducted with tablets. Thus, valid information about product components that are linked to a certain product strategy (represented by semantic concepts) as well as special design rules for emotional product design are deduced. Furthermore, support for the educated decision in favor of a special design alternative can be given. The presented methodology and the results are an excerpt of an holistic approach, that is also analyzing bio-signals in order to quantify the emotional response and to evaluate what customer's might really feel whilst focusing a product alternative. So, deeper analysis of the recorded Eye-Tracking data can be done in order to interpret the meaning why subjects really focus one component longer than another. [4] Furthermore, the study design based on pictures of the product and product components might be validated by a physical study which could supported by an mobile Eye-Tracking system.

\section{Acknowledgement}

The paper presents results from the cooperative research project CONEMO (funded by CORNET program) of the Laboratory for Machine Tools and Production Engineering (WZL), RWTH Aachen University, Germany together with the Institute of Biomechanics of Valencia (IBV), Spain. The funding agencies are IMPIVA (Operational Programme FEDER of the Comunidad Valenciana, Spain) and AiF (Germany). The CORNET promotion plan 47EN of the Research Community for Quality (FQS), August-Schanz-Str. 21A, 60433 Frankfurt/Main has been funded by the AiF within the program for sponsorship by Industrial Joint Research and Development (IGF) of the German Federal Ministry of Economic Affairs and Technologies based on an enactment of the German Parliament. The authors would like to express their gratitude to all parties involved.

\section{References}

1. M. Köhler, R. Schmitt: Systematic Consumer Evaluation Measurement for Objectified Integration into the Product Development Process (In: Ji, Y. G.: Advances in Affective and Pleasurable Design, CRC Press, pp.503-512, 2012)

2. R. Jiao, Y. Zhang, M. Helander: Kansei mining system for affective design, (In: Expert Systems with Applications, 4, pp. 658-673, 2006)

3. P. Beaujean, R. Grob, K. Häfen, E. Köbler, M. Köhler, B. Quattelbaum, R. Schmitt, R Seitz, M. Wagner, A. Willach: Emotionale Produktgestaltung - Wert der wahrgenommenen Qualität, (In: Brecher et al.: Wettbewerbsfaktor Produktionstechnik: Aachener Perspektiven, Aachen, 2011)

4. R. Schmitt, M. Köhler, J. Durá, J, Diaz-Pineda: Objectifying User attention and emotion evoked by relevant perceived product components. (In: Proceedings of 11th International Symposium on Measurement Technology and Intelligent Instruments ISMTII, 2013)

5. B. Falk, R. Schmitt, B. Quattelbaum: Product Quality from the Customers' Perspective Systematic Elicitation and Deployment of Perceived Quality Information, (In: Proceedings of the 6th CIRP-Sponsored International Conference on Digital Enterprise Technology, pp. 216, 2008).

6. R. Schmitt, B. Quattelbaum, H. Lieb: Perceived quality as a key factor for strategic change in product development. (In: IEEE International Engineering Management Conference, pp. 311-316, New Jersey, 2008)

7. R. Schmitt, T. Pfeifer: Qualitätsmanagement: Strategien-Methoden-Techniken, München (2010)

8. N. Berghaus: Eye-Tracking im stationären Einzelhandel. Eine empirische Analyse der Wahrnehmung von Kunden am Point of Purchase, dissertation, University Duisburg-Essen, (2005)

9. A. T. Duchowski: Eye Tracking Methodology: Theory and Practice, Vol. 2., London, (2007)

10. N. Hofer, W. Mayerhofer: Die Blickregistrierung in der Werbewirkungsforschung. Grundlagen und Ergebnisse, (In: Der Markt, No. 49, pp. 149, 2010)

11. C. Mello-Thoms, C.F. Nodine, H.L. Kundel: What attracks the eye to the location of missed and reported breast cancers? (In: Proceedings of the Eye Tracking Research and Applications Symposium 2002, pp. 111-117, NY, ACM Press, 2004)

12. B. Hoeks, W.J.M. Levelt: Pupillary dilation as a measure of attention: A quantitative system analysis. (In: Behavior Research Methods, Instruments, \& Computers, 25, 16-26, 1993)

13. J.A. Stern, D. Boyer, D. Schroeder: Blink rate: a possible measure of fatigue. (In: Human Factors 36 2, pp. 285-297, 1994)

14. S. Schütte: Designing Feelings into Products. Integrating Kansei Engineering Methodology in Product Development, dissertation, University Linköping, (2002).

15. E. Czerwinski, M. Horvitz, E. Cutrell: Subjective duration assessment: an implicit probe for software usability, (In: Proceedings of the IHM-HCI 2001 Conference, Vol. 2, pp. 167-170, 2001)

16. J. Nielsen, J. Levy, Measuring usability: preference vs. performance. (In: Communications of the ACM 37, No. 4, pp. 66-75, 1994)

17. A. L. Yarbus, Eye Movements and Vision, Plenum Press (1967)

18. N. Kano: Attractive quality and must-be quality, (In : J. of the Japanese Society for Quality Control, 4, pp. 39-48, 1984)

19. D. Fong, Using the self-stated importance questionnaire to interpret Kano (1996)

20. L. Issing, H. Mikasch: Blickbewegung und Bildverarbeitung. Kognitionspsychologische Aspekte visueller Informationverarbeitung. (In: J. Haack (ed.): Blickbewegung und Bildverarbeitung), Frankfurt am Main, 1986) 